\title{
Metastasis to lateral lymph nodes with no mesenteric lymph node involvement in low rectal cancer: a retrospective case series
}

\author{
Peng Li, Zhichun Zhang, Yuanda Zhou, Qingsheng Zeng, Xipeng Zhang ${ }^{*+}$ and Yi Sun ${ }^{*+}$
}

\begin{abstract}
Purpose: The aim of this study is to examine the pattern of lymph node metastasis (lateral vs. mesenteric lymph nodes) in low rectal cancer.

Methods: This retrospective analysis included all patients undergoing laparoscopic total mesorectal excision plus lateral lymph node dissection for advanced low rectal cancer (up to $8 \mathrm{~cm}$ from the anal verge) during a period from July 1, 2017, to August 31, 2019, at the Department of Colorectal Surgery, Tianjin Union Medical Center. The decision to conduct lateral lymph node dissection was based on positive findings in preoperative imaging assessments.

Results: A total of 42 patients were included in data analysis. Surgery was successfully completed as planned, without conversion to open surgery in any case. A minimum of 10 mesenteric lymph nodes and 1 lateral lymph node on each side were dissected in all patients. Pathologic examination of resected specimens showed no metastasis to either mesenteric or lateral lymph nodes in $7(16.7 \%)$ case, metastasis to both mesenteric and lateral lymph nodes in 26 (61.9\%) cases, metastasis to mesenteric but not lateral lymph nodes in 4 (9.5\%) cases, and metastasis to lateral but not mesenteric lymph nodes in 5 (11.9\%) cases ( $n=2$ in the obturator region; $n=3$ in the iliac artery region).

Conclusion: A clinically significant proportion of low rectal cancer patients have metastasis to lateral lymph nodes without involvement of mesenteric lymph nodes. More carefully planned prospective studies are needed to verify this preliminary finding.
\end{abstract}

\section{Introduction}

In patients with low rectal cancer (up to $8 \mathrm{~cm}$ from the anal verge), estimated rate of lateral lymph node metastasis is $16-23 \%$ [1]. The most recent Japanese Society for Cancer of the Colon and Rectum (JSCCR) Guidelines for the treatment of colorectal cancer classify metastasis to lateral lymph nodes as local metastasis and recommend lateral lymph node dissection (LLND) in both stage II and III low rectal cancers [2]. The NCCN Guidelines recommend chemoradiotherapy (CRT) plus total mesorectal excision (TME) treatment for lateral lymph node metastasis

\footnotetext{
* Correspondence: zhangxipeng@vip.tom.com; sunvi@vip.tom.com ${ }^{+}$Xipeng Zhang and Yi Sun contributed equally to this work. Department of Colorectal Surgery, Tianjin Union Medical Center, Tianjin 300000 , China
}

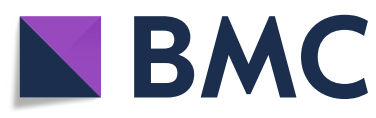

(0) The Author(s). 2020 Open Access This article is licensed under a Creative Commons Attribution 4.0 International License, which permits use, sharing, adaptation, distribution and reproduction in any medium or format, as long as you give appropriate credit to the original author(s) and the source, provide a link to the Creative Commons licence, and indicate if changes were made. The images or other third party material in this article are included in the article's Creative Commons licence, unless indicated otherwise in a credit line to the material. If material is not included in the article's Creative Commons licence and your intended use is not permitted by statutory regulation or exceeds the permitted use, you will need to obtain permission directly from the copyright holder. To view a copy of this licence, visit http://creativecommons.org/licenses/by/4.0/. The Creative Commons Public Domain Dedication waiver (http://creativecommons.org/publicdomain/zero/1.0/) applies to the data made available in this article, unless otherwise stated in a credit line to the data.

[3]. A recent study reported 19.5\% 5-year local recurrence rate after CRT plus TME versus 5.5\% 5-year local recurrence rate after CRT plus TME and LLND in patients with lateral lymph nodes at least $7 \mathrm{~mm}$ in diameter, supporting the notion that lateral lymph node involvement represents local metastasis [4].

In this retrospective analysis, we examined the metastasis profile (lateral vs. mesenteric lymph nodes) in a group of low rectal cancer patients with suspected lateral lymph node involvement based on preoperative imaging assessments. The results showed metastasis to lateral but not mesenteric lymph nodes in 5 out of 42 patients, supporting the notion that lateral lymph node metastasis should be regarded as local metastasis. 


\section{Patients and methods}

We identified all patients receiving laparoscopic TME plus lateral lymph node dissection for advanced low rectal cancer (up to $8 \mathrm{~cm}$ from the anal verge on magnetic resonance imaging $(\mathrm{MRI})$ ) during a period from July 1, 2017, to August 31, 2019, at the Department of Colorectal Surgery, Tianjin Union Medical Center.

If the short diameter of the largest lymph node was at least $7 \mathrm{~mm}$ in diameter in MRI or the rectal lesions accord with the standard of neoadjuvant CRT therapy evaluated by a multidisciplinary team, neoadjuvant CRT was recommended to the patients. In long-course radiotherapy, a total dose of 45-50 Gy was given over 5 weeks. Typical chemotherapy regimen was CapeOX: two cycles of an intravenous oxaliplatin $\left(130 \mathrm{mg} / \mathrm{m}^{2}\right.$ per day) for 1 day and oral capecitabine (1000 mg/m $\mathrm{m}^{2}$ twice per day) for 14 days in the first and fourth weeks of radiotherapy. The short diameter of the largest lymph was re-evaluated after neoadjuvant therapy. If the preoperative short diameter of the largest lymph node was at least $5 \mathrm{~mm}$, TME + LLND was performed 6-8 weeks after neoadjuvant CRT. If the patient refused to receive neoadjuvant CRT, TME + LLND was performed immediately.

TME and lateral lymph node dissection were performed using a fascial space priority approach, as previously described [5].

\section{Statistical analysis}

In addition to descriptive statistics, we also compared the demographic and pathologic features among subjects with different metastasis pattern (i.e., metastasis to both mesenteric and lateral, metastasis to mesenteric but not lateral, and metastasis to lateral but not mesenteric lymph nodes). Continuous variables are expressed as mean \pm standard deviation if following normal distribution, and as median (range) otherwise. Categorical variables are presented as numbers (\%). All analyses were conducted using SPSS Statistics (Version 25.0).

\section{Results}

A total of 42 patients were included in data analysis. Surgery was completed as planned, with no conversion to open surgery. Median distance from the lesion to the anal verge was $4.8 \mathrm{~cm}$ (range $0-8$ ) (Table 1). Sixteen patients received neoadjuvant CRT. Twenty-eight patients received unilateral lateral lymph node dissection, and the remaining 14 patients received bilateral dissection. A minimum of 10 mesenteric lymph nodes and 1 lateral lymph node on each side were dissected in all patients.

Metastasis was verified in both mesenteric and lateral lymph nodes in 26 (61.9\%) patients, in mesenteric but not in lateral lymph nodes in $4(9.5 \%)$ patients, and in lateral but not mesenteric lymph nodes in 5 (11.9\%) patients. In the 5 cases with metastasis to lateral but not mesenteric lymph nodes, involved lymph nodes were in the obturator region in 2 cases, and in the iliac artery region in the remaining 3 cases.

Surgical approach, pathologic staging, and the extent of lymph node dissection in the entire study sample and in patients with different patterns of lymph node metastasis are shown in Table 2. The median follow-up in the 5 patients with lateral but no mesenteric lymph node metastasis was 13 (1-31) months; no recurrence was observed.

\section{Discussion}

In a previous study, we reported a fascial space priority approach for lateral lymph node dissection in patients with rectal cancer [5]. Using this approach, we found in the current study that 5 out of a total of 42 patients $(11.9 \%)$ with low rectal cancer had metastasis to lateral lymph nodes but not to mesenteric lymph nodes. This finding supports

Table 1 Demographic and clinical characteristics

\begin{tabular}{|c|c|c|c|c|c|}
\hline & $\begin{array}{l}\text { Entire sample } \\
(n=42)\end{array}$ & $\begin{array}{l}\text { meso+, lat+ } \\
(n=26)\end{array}$ & $\begin{array}{l}\text { meso+, lat- } \\
(n=4)\end{array}$ & $\begin{array}{l}\text { meso-, lat+ } \\
(n=5)\end{array}$ & $\begin{array}{l}\text { meso-, lat- } \\
(n=7)\end{array}$ \\
\hline Age (years), mean \pm SD & $58.79 \pm 10.69$ & $58.23 \pm 11.14$ & $64.75 \pm 12.09$ & $58.80 \pm 6.53$ & $57.43 \pm 11.66$ \\
\hline Male sex, $n(\%)$ & $24(57.1)$ & $16(61.5)$ & $2(50.0)$ & $2(40.0)$ & $4(57.1)$ \\
\hline $\mathrm{BMI}\left(\mathrm{kg} / \mathrm{m}^{2}\right)$, mean $\pm \mathrm{SD}$ & $24.61 \pm 3.37$ & $24.48 \pm 3.37$ & $24.52 \pm 5.32$ & $25.56 \pm 3.56$ & $24.64 \pm 2.72$ \\
\hline Distance from AV (cm), median (range) & $4.8(0-8)$ & $4.55(0-8)$ & $5.65(1-8)$ & $4.8(3-5.5)$ & $5.6(3.5-8)$ \\
\hline \multicolumn{6}{|l|}{ cT Stage, $n(\%)$} \\
\hline $\mathrm{ct} 2$ & $2(4.8)$ & & & & $1(14.3)$ \\
\hline сT3 & $31(73.8)$ & $21(80.8)$ & $3(75.0)$ & $4(80.0)$ & $4(57.1)$ \\
\hline cT4 & $9(21.4)$ & $5(19.2)$ & $1(25.0)$ & $1(20.0)$ & $2(28.6)$ \\
\hline \multicolumn{6}{|l|}{ cN Stage, n (\%) } \\
\hline cN1 & $21(50.0)$ & $10(38.5)$ & $1(25)$ & $5(100)$ & $4(57.1)$ \\
\hline $\mathrm{cN} 2$ & $21(50.0)$ & $16(61.5)$ & $3(75)$ & & $3(42.9)$ \\
\hline nCRT, n (\%) & $16(38.1)$ & $10(38.5)$ & $1(25.0)$ & $2(40)$ & $3(42.9)$ \\
\hline
\end{tabular}

$A V$ anal verge, $B M I$ body mass index, lat lateral lymph nodes, meso mesenteric lymph nodes 
Table 2 Surgical and pathologic characteristics

\begin{tabular}{|c|c|c|c|c|c|}
\hline & $\begin{array}{l}\text { Entire sample } \\
(n=42)\end{array}$ & $\begin{array}{l}\text { meso+, lat+ } \\
(n=26)\end{array}$ & $\begin{array}{l}\text { meso+, lat- } \\
(n=4)\end{array}$ & $\begin{array}{l}\text { meso- }, \text { lat+ } \\
(n=5)\end{array}$ & $\begin{array}{l}\text { meso-, lat- } \\
(n=7)\end{array}$ \\
\hline \multicolumn{6}{|l|}{ Surgical approach, $n$ (\%) } \\
\hline Abdominoperineal resection & 18 & $10(38.5)$ & $2(50.0)$ & $2(40)$ & $4(57.1)$ \\
\hline Anterior resection & 19 & $12(46.2)$ & $1(25.0)$ & $3(60)$ & $3(42.9)$ \\
\hline Hartmann's procedure & 5 & $4(15.4)$ & $1(25.0)$ & & \\
\hline \multicolumn{6}{|l|}{ LLND dissection, $n(\%)$} \\
\hline Unilateral & 28 & $13(50.0)$ & $3(75.0)$ & $5(100)$ & $7(100)$ \\
\hline Bilateral & 14 & $13(50.0)$ & $1(25.0)$ & & \\
\hline \multicolumn{6}{|l|}{ TNM stage, $n(\%)$} \\
\hline 0 & $1(2.4)$ & & & & $1(14.3)$ \\
\hline । & $1(2.4)$ & & & & $1(14.3)$ \\
\hline$\|$ & $4(9.5)$ & & & & $4(57.1)$ \\
\hline III & $35(83.3)$ & $25(96.2)$ & $4(100)$ & $5(100)$ & $1(14.3)$ \\
\hline IV & $1(2.4)$ & $1(3.8)$ & & & \\
\hline \multicolumn{6}{|l|}{ Mesenteric lymph nodes, M (range) } \\
\hline No. of dissection per patient & $3(0-23)$ & $17(10-29)$ & $17.5(12-20)$ & $16(12-21)$ & $15(11-25)$ \\
\hline No. of metastasis per patient & $16.5(10-29)$ & $4.5(1-23)$ & $5(2-10)$ & 0 & 0 \\
\hline \multicolumn{6}{|l|}{ Lateral lymph nodes, M (range) } \\
\hline No. of dissection per each side & $7.5(1-41)$ & $6(1-41)$ & $15(7-24)$ & $8(3-13)$ & $8(4-19)$ \\
\hline No. of metastasis per each side & $1(0-10)$ & $1(0-10)$ & 0 & $1(1-2)$ & 0 \\
\hline \multicolumn{6}{|c|}{ Metastatic lymph node location, $n(\%)$} \\
\hline Iliac artery region & & & & $3(60)$ & \\
\hline Obturator region & & & & $2(40)$ & \\
\hline
\end{tabular}

lat lateral lymph nodes, meso mesenteric lymph nodes, (-) negative, (+) positive

managing lateral lymph node involvement as local metastasis [6-8] and suggests the possibility that lateral lymph nodes may be sentinel lymph nodes in some patients.

Lymphatic drainage of the lower rectum passes to external pelvic (inguinal area) or pelvic (iliac vessels and anterior sacral) lymph nodes, or to the root of inferior mesenteric artery along the superior rectal artery. In a study by Akiyoshi and colleagues, prognosis did not differ significantly between patients with $\mathrm{N} 2 \mathrm{a}$ and those with lymph node metastasis either in the external iliac artery region (5year overall survival, $45 \%$ vs $45 \%, P=0.9585$; 5 -year cancer-specific survival: $51 \%$ vs $49 \%, P=0.5742$ ) or in the internal iliac artery region (5-year overall survival: $32 \%$ vs $29 \%, P=0.3342$; 5 -year cancer-specific survival: $37 \%$ vs $34 \%, P=0.4347$ ) [9], suggesting that the lateral lymph node involvement should be regarded as local metastasis. The findings from the current study supported such a notion. Lymphatic mapping technology can be adopted to study drainage pattern of low rectal cancer [10].

Few studies have examined the prognosis of patients with lateral lymph node metastasis but no mesenteric lymph node metastasis. Based on a study by Takahashi et al. [6], the 5-year survival rate was $90.1 \%$ in patients with no metastasis to either mesenteric or lateral lymph nodes, $75 \%$ in patients with metastasis to lateral but not mesenteric lymph nodes, $67.7 \%$ in patients with metastasis to mesenteric but not lateral lymph nodes, and $32 \%$ in patients with metastasis to both lateral and mesenteric lymph nodes. Akiyoshi and colleagues argued that metastasis to lymph nodes located in the area medial to internal iliac artery should be classified as N2a and those located in the area lateral to internal iliac artery should be classified as N2b [9]. Despite such detailed differences, the prognosis of patients with metastasis to lateral but not mesenteric lymph nodes is clearly better than in patients with metastasis to both lateral and mesenteric lymph nodes. Studies with larger sample size and with a focus on the long-term survival in patients with distinct lymph node metastasis (lateral vs mesenteric) are needed to examine the clinical significance.

Lateral lymph node dissection could influence pathologic staging and hence postoperative management of the patients. In the current study, the 5 patients with metastasis to lateral but not mesenteric lymph nodes would have been classified as pNO and stage II if lateral lymph nodes were not dissected. With erroneous staging, adjuvant chemotherapy after surgery would not be recommended. In low rectal 
cancer patients with MRI evidence for lateral lymph node involvement but no metastasis to mesenteric lymph node, CRT should be initiated; in patients who do not respond to CRT, LLND should be conducted. For patients with no mesenteric lymph node metastasis upon pathologic examination (regardless of the lateral lymph node status), the 2020 NCCN Guideline recommends the "watch and wait" approach. The results from the current study suggest that more attention should be given to lateral lymph node metastasis after neoadjuvant chemoradiation [3].

The AJCC colorectal cancer staging Guideline [11] classifies lymph nodes in the iliac artery region as regional, but considers metastasis to lymph nodes in obturator artery region as distant metastasis. Two patients in the current study had metastasis to lymph nodes in the obturator but not iliac artery lymph nodes or mesenteric lymph nodes. Based on this finding, we speculate that obturator lymph nodes should also be regarded as regional. Cirocchi et al. reported that the pooled prevalence estimate of LCA absence was $1.2 \%$ (95\% CI $0.0-3.6 \%)$. This rare absence of the left colonic artery/superior rectal artery or variation in lymphatic drainage may also contribute to this phenomenon [12]. Due to very small number of the cases, this speculation must be examined in future studies.

There are several important limitations in the current study. First, this is a retrospective analysis of the patients receiving TME plus LLND for low rectal cancer. Due to the retrospective nature, there were no strict criteria for LLND. Nevertheless, we adopted a general set of indications for LLND. Another important limitation is the use of neoadjuvant CRT in some but not all patients, which may have influenced the pathologic staging. Third, we did not conduct systematic follow-up. As a result, the clinical significance of metastasis to lateral but not mesenteric lymph nodes remains ambiguous. The sample size is also relatively small, and we could not compare the baseline features across patients with different pattern of lymph node metastasis.

\section{Conclusion}

A clinically meaningful proportion of low rectal cancer patients had metastasis to lateral but not mesenteric lymph nodes. The presence of this group of patients indicates a need to re-evaluate whether metastasis to lateral lymph nodes represents local or distant metastasis.

\section{Acknowledgements}

The authors acknowledge the contribution of all patients involved in this study.

\section{Authors' contributions}

Xipeng Zhang and Yi Sun conceptualized the study. Peng Li, Zhichun Zhang, Yuanda Zhou, and Qingsheng Zeng collected the data. Peng Li analyzed the data and drafted the manuscript. All authors reviewed, edited, and agreed on the final draft of the manuscript. The authors read and approved the final manuscript.

\section{Funding}

This study was supported by Wu Jieping Medical Foundation (320.2710.1821) and Research

Project of Tianjin Union Medical Center (2019ZDXK03).

Availability of data and materials

The dataset is available upon request.

\section{Ethics approval and consent to participate}

The study has been conducted in accordance with the Declaration of Helsinki. Informed consent was obtained from all participants. The study was approved by the Ethics Committee of Tianjin Union Medical Center. The number of ethic is 2020-B04.

\section{Consent for publication}

All authors have provided their consent for publication of the manuscript.

\section{Competing interests}

All authors have declared no potential competing interests.

Received: 4 June 2020 Accepted: 26 October 2020

Published online: 06 November 2020

References

1. Yang X, Gu C, Hu T, Bi L, Wei M, Deng X, et al. Is laparoscopic selective lateral lymph node dissection for locally advanced rectal cancer after neoadjuvant chemoradiotherapy safe? ANZ J Surg. 2019;89(11):E492-7. https://doi.org/10.1111/ans.15449.

2. Hashiguchi Y, Muro K, Saito Y, Ito Y, Ajioka Y, Hamaguchi T, et al. Japanese Society for Cancer of the colon and Rectum (JSCCR) guidelines 2019 for the treatment of colorectal cancer. Int J Clin Oncol. 2020;25(1):1-42. https://doi. org/10.1007/s10147-019-01485-z.

3. Benson AB, Venook AP, Al-Hawary MM, Arain MA, Chen YJ, Ciombor KK, et al. Rectal cancer, version 1.2020, NCCN clinical practice guidelines in oncology; 2020.

4. Ogura A, Konishi T, Cunningham C, Garcia-Aguilar J, Iversen H, Toda S, et al. Neoadjuvant (chemo)radiotherapy with total mesorectal excision only is not sufficient to prevent lateral local recurrence in enlarged nodes: results of the multicenter lateral node study of patients with low cT3/4 rectal cancer. J Clin Oncol. 2019;37(1):33-43. https://doi.org/10.1200/jco.18.00032.

5. Sun Y, Zhang Z, Zhou Y, Zhang X. Fascial space priority approach in laparoscopy: lateral pelvic lymph node dissection for advanced low rectal cancer. Tech Coloproctol. 2020;24(4):335-6. https://doi.org/10.1007/s10151-020-02178-w.

6. Takahashi T, Ueno M, Azekura K, Ohta H. Lateral node dissection and total mesorectal excision for rectal cancer. Dis Colon Rectum. 2000;43(10 Suppl): S59-68. https://doi.org/10.1007/bf02237228.

7. Baik SH, Kim NK, Lee YC, Kim H, Lee KY, Sohn SK, et al. Prognostic significance of circumferential resection margin following total mesorectal excision and adjuvant chemoradiotherapy in patients with rectal cancer. Ann Surg Oncol. 2007;14(2):462-9. https://doi.org/10.1245/s10434-006-9171-0.

8. Akiyoshi T, Ueno M, Matsueda K, Konishi T, Fujimoto Y, Nagayama S, et al. Selective lateral pelvic lymph node dissection in patients with advanced low rectal cancer treated with preoperative chemoradiotherapy based on pretreatment imaging. Ann Surg Oncol. 2014;21(1):189-96. https://doi.org/10.1245/s10434-013-3216-y.

9. Akiyoshi T, Watanabe T, Miyata S, Kotake K, Muto T, Sugihara K. Results of a Japanese nationwide multi-institutional study on lateral pelvic lymph node metastasis in low rectal cancer: is it regional or distant disease? Ann Surg. 2012;255(6):1129-34. https://doi.org/10.1097/SLA.0b013e3182565d9d.

10. Bell S, Sasaki J, Sinclair G, Chapuis PH, Bokey EL. Understanding the anatomy of lymphatic drainage and the use of blue-dye mapping to determine the extent of lymphadenectomy in rectal cancer surgery: unresolved issues. Color Dis. 2009;11(5):443-9. https://doi.org/10.1111/j.1463-1318.2009.01769.x.

11. Weiser MR. AJCC 8th edition: colorectal cancer. Ann Surg Oncol. 2018;25(6): 1454-5. https://doi.org/10.1245/s10434-018-6462-1.

12. Cirocchi R, Randolph J, Cheruiyot I, Davies JR, Wheeler J, Lancia M, et al. Systematic review and meta-analysis of the anatomical variants of the left colic artery. Color Dis. 2020;22(7):768-78. https://doi.org/10.1111/codi.14891 Epub 2019 Nov 21. PMID: 31655010.

\section{Publisher's Note}

Springer Nature remains neutral with regard to jurisdictional claims in published maps and institutional affiliations. 